\title{
Effects of Korean Red Ginseng extract on tissue plasminogen activator and plasminogen activator inhibitor-1 expression in cultured rat primary astrocytes
}

\author{
Hyun Myung Ko ${ }^{1}$, So Hyun Joo ${ }^{1}$, Pitna Kim르 Jin Hee Park ${ }^{1}$, Hee Jin Kim ${ }^{1}$, Geon Ho Bahn², \\ Hahn Young Kim ${ }^{1}$, Jongmin Lee ${ }^{1}$, Seol-Heui Han ${ }^{1}$, Chan Young Shin ${ }^{1 *}$, and Seung Hwa Park ${ }^{1,3^{*}}$ \\ ${ }^{1}$ Department of Neuroscience, School of Medicine and Neuroscience Research Center, Institute SMART-IABS, Konkuk \\ University, Seoul 143-701, Korea \\ ${ }^{2}$ Department of Neuropsychiatry, School of Medicine, Kyung Hee University, Seoul 130-701, Korea \\ ${ }^{3}$ Department of Anatomy, School of Medicine, Konkuk University, Seoul 143-701, Korea
}

Korean Red Ginseng (KRG) is an oriental herbal preparation obtained from Panax ginseng Meyer (Araliaceae). To expand our understanding of the action of KRG on central nervous system (CNS) function, we examined the effects of KRG on tissue plasminogen activator (tPA)/plasminogen activator inhibitor-1 (PAI-1) expression in rat primary astrocytes. KRG extract was treated in cultured rat primary astrocytes and neuron in a concentration range of 0.1 to $1.0 \mathrm{mg} / \mathrm{mL}$ and the expression of functional tPA/PAI-1 was examined by casein zymography, Western blot and reverse transcription-polymerase chain reaction. KRG extracts increased PAI-1 expression in rat primary astrocytes in a concentration dependent manner (0.1 to $1.0 \mathrm{mg} / \mathrm{mL})$ without affecting the expression of tPA itself. Treatment of $1.0 \mathrm{mg} / \mathrm{mL}$ KRG increased PAI-1 protein expression in rat primary astrocytes to $319.3 \pm 65.9 \%$ as compared with control. The increased PAI-1 expression mediated the overall decrease in tPA activity in rat primary astrocytes. Due to the lack of PAI-1 expression in neuron, KRG did not affect tPA activity in neuron. KRG treatment induced a concentration dependent activation of PI3K, p38, ERK1/2, and JNK in rat primary astrocytes and treatment of PI3K or MAPK inhibitors such as LY294002, U0126, SB203580, and SP600125 (10 $\mu \mathrm{M}$ each), significantly inhibited $1.0 \mathrm{mg} / \mathrm{mL}$ KRG-induced expression of PAI1 and down-regulation of tPA activity in rat primary astrocytes. Furthermore, compound $\mathrm{K}$ but not other ginsenosides such as Rb1 and Rg1 induced PAI-1 expression. KRG-induced up-regulation of PAI-1 in astrocytes may play important role in the regulation of overall tPA activity in brain, which might underlie some of the beneficial effects of KRG on CNS such as neuroprotection in ischemia and brain damaging condition as well as prevention or recovery from addiction.

Keywords: Panax ginseng, Compound K, Tissue plasminogen activator, Plasminogen activator inhibitor-1, Astrocyte

\section{INTRODUCTION}

Astrocytes are the most abundant type of cells in the brain, which regulate energy and ion homeostasis of extracellular milieu in central nervous system (CNS). Astrocytes not only provide structural support in CNS

cc This is an Open Access article distributed under the terms of the Creative Commons Attribution Non-Commercial License (http://creativecommons.org/licenses/by-nc/3.0/) which permits unrestricted non-commercial use, distribution, and reproduction in any medium, provided the original work is properly cited.

(C) The Korean Society of Ginseng but also actively involved in the proper maintenance of synaptic environment by dozens of mechanisms such as trophic support, anti oxidant defense, neurotransmitter uptake, production of proteases and protease inhibitors

Edited by Ki Sung Kang, Korea Institute of Science and Technology, Korea

Received 15 Mar. 2013, Revised 20 May. 2013, Accepted 24 May. 2013

*Corresponding authors

E-mail: seunghwa.park@kku.ac.kr

E-mail: chanyshin@kku.ac.kr

Tel: +82-2-2030-7835, Fax: +82-2-2030-7899 
and modulation of extracellular matrix components [1].

Tissue plasminogen activator (tPA) and its endogenous inhibitor plasminogen activator inhibitor-1 (PAI1) is not only involved in clot dissolution in peripheral blood vessel, but also plays important role in brain such as regulation of neurite outgrowth, cell migration during development, regulation of synaptic plasticity and much more [2,3]. It is also clear that the tight regulation of this enzymatic system is important because they are involved in the regulation of cellular function and pathogenesis of several CNS disorders including addiction, Alzheimer's disease, multiple sclerosis, spinal cord injury, fetal alcohol spectrum disorder and stroke [2-4].

Although most of the cells in CNS express tPA, PAI-1 is exclusively expressed in astrocytes [5] and the regulation of PAI-1 activity and expression plays important role in the modulation of overall tPA activity in brain. Considering tPA/PAI-1 may play both protective and destructive role in cellular function as well as cell survival, it is very important to understand the regulatory mechanism of tPA/PAI-1 in brain, which may provide better way to control a myriad of neurological processes ranging from cellular differentiation and synaptic plasticity to neuronal death and regeneration.

Korean Red Ginseng (KRG) is an oriental herbal preparation used for medicinal and nutritional supplemental purposes. KRG is obtained from Panax ginseng by a series of process including drying, heating and steaming. Studies using both human and animal models suggested that ginseng and related compounds provides beneficial effects in many CNS diseases including Alzheimer's disease, addiction, depression and stroke [6-10]. However, no reports are available regarding the role of KRG on tPA/PAI-1 system in brain cells. Studies using endothelial and vascular smooth muscle cells suggested that ginseng or ginsenosides may affect tPA and PAI-1 activity and expression in a variety of different ways [11-16].

In this study, we examined the effects of KRG on tPA/ PAI-1 system in rat primary neuron and astrocytes. The results show that KRG and ginsenoside compound $\mathrm{K}$ (CK) up-regulates PAI-1 in astrocytes thereby downregulate $\mathrm{tPA}$ activity in rat primary astrocytes. The regulation of tPA/PAI-1 activity by KRG and CK may contribute to the KRG's effects on various CNS conditions and diseases.

\section{MATERIALS AND METHODS}

\section{Materials}

Dulbecco's modified Eagle medium (DMEM)/F12, fe- tal bovine serum (FBS), and other culture reagents were obtained from Gibco BRL (Grand Island, NY, USA). Bovine plasminogen and urokinase was obtained from American Diagnostica (Stamford, CT, USA). Lipopolysaccharide (LPS, serotype O26:B6) and other chemicals including casein were purchased from Sigma (St. Louis, MO, USA). SB203580, SP600125, U0126, and LY294002 were obtained from Calbiochem (La Jolla, CA, USA). Rabbit polyclonal antibody against rat PAI-1 was obtained from American Diagnostica. Phosphospecific or total antibodies to ERK1/2, JNK, p38, PI3K, Akt, and $\mathrm{I} \kappa \mathrm{B} \alpha$ were obtained from Cell Signaling (Beverly, MA, USA). Ginsenosides CK, Rb1, and Rg1 was purchased from Ambo Institute (Seoul, Korea). Standardized KRG was manufactured and kindly provided by Korea Ginseng Corporation (Seoul, Korea). The preparation of KRG and analysis of the composition of major ginsenosides in the extract were reported previously [17]. In brief, roots of a 6-year-old fresh $P$. ginseng were extracted three times at $85^{\circ} \mathrm{C}$ to $90^{\circ} \mathrm{C}$ for $8 \mathrm{~h}$ with circulating hot water. The water content of pooled extract was $36 \%$ of total weight.

\section{Rat primary astrocyte culture}

All animal experimental procedures were carried out using protocols approved by the Institutional Animal Care and Use Committee of the Konkuk University. Sprague-Dawley (SD) rat pups were obtained from Samtako (Seoul, Korea). Cultured rat astrocytes were prepared as described previously [5]. Briefly, prefrontal cortices of 2-day-old SD rat pups were dissected out and digested with trypsin for $10 \mathrm{~min}$ at $37^{\circ} \mathrm{C}$. A single cell suspension was obtained by trituration, and cells were seeded onto poly-d-lysine $(20 \mu \mathrm{g} / \mathrm{mL})$ coated plates. Cultures were maintained in DMEM/F12 with $10 \%$ heatinactivated fetal bovine serum, $100 \mathrm{U} / \mathrm{mL}$ penicillin, and $100 \mathrm{mg} / \mathrm{mL}$ streptomycin. Confluent cells were rinsed twice with serum-free media and then detached with $0.25 \%$ trypsin with ethylenediaminetetraacetic acid and subcultured by replating at low density $\left(5,000\right.$ cells $\left./ \mathrm{cm}^{2}\right)$ in 24-well or six-well plates (Becton-Dickinson, Franklin Lakes, NJ, USA). Cells reached confluence within 10 days after subculture, and 13 to 14-day-old cells were used for this study. At this point, more than 95\% of cells were glial fibrillary acidic protein-positive astrocytes, as described previously [18].

\section{Rat primary cortical neuron culture}

Cultured rat cortical neurons were prepared as described previously [5]. Briefly, primary cortical neurons 
were obtained from embryonic day 18 cortex of SD rats. The cortices were mechanically triturated three times with a flame-polished Pasteur pipette in the culture medium (Eagle's minimal essential medium supplemented with $20 \mathrm{mM}$ glucose, 5\% FBS, 5\% horse serum, and 2 $\mathrm{mM}$ glutamine). The cells were seeded onto $50 \mu \mathrm{g} / \mathrm{mL}$ poly-d-lysine-coated plate in the culture medium. The cultures were maintained at $37^{\circ} \mathrm{C}$ in a humidified $5 \%$ $\mathrm{CO}_{2}$ incubator.

\section{Drug treatment}

Cells were washed twice with serum-free media and then treated with $0.1,0.5$, or $1.0 \mathrm{mg} / \mathrm{mL} \mathrm{KRG}$ or ginsenosides CK, Rb1, or Rg1(1, 5, or $10 \mu \mathrm{M})$ for 24 h under serum-free conditions to prevent the contamination of casein-digesting activity from serum. After each treatment, the culture supernatants were collected and assayed for tPA/PAI-1 activity. In some cases, MAPK inhibitors (10 $\mu \mathrm{M})$ such as U0126, SB203580, SP600125, or a PI3K inhibitor LY294002 were pretreated for 30 min before KRG treatment (1.0 mg/mL). In all assay conditions used in this study, no cellular toxicity was observed, as determined by morphological examination and 3-[4,5-dimethylthiazol-2-yl]-2,5-diphenyl-tetrazolium bromide (MTT) assay.

\section{Measurement of cell viability}

Cultured cortical neurons and astrocytes were treated with KRG. After 24 h, cell viability was assessed by MTT assay. MTT is a water-soluble tetrazolium salt that is reduced by metabolically viable cells to a colored, water-insoluble formazan salt. MTT (1 mg/mL) was added to the cell culture medium. After incubating the plates at $37^{\circ} \mathrm{C}$ for $2 \mathrm{~h}$ in a $5 \% \mathrm{CO}_{2}$ atmosphere, the MTTcontaining medium was replaced with dimethylsulfoxide. The absorbance was read at $570 \mathrm{~nm}$ with a microplate reader (Spectramax 190; Molecular Devices, Palo Alto, CA, USA).

\section{Casein zymography}

The tPA activity was determined by casein zymography as described previously [5]. Cell lysates or culture supernatants from astrocyte or neuron culture were mixed with sample buffer (sodium dodecyl sulfate [SDS]polyacrylamide gel electrophoresis [PAGE] sample buffer lacking $\beta$-mercaptoethanol). Samples were resolved by electrophoresis on $8 \%$ polyacrylamide gel containing $0.1 \%$ SDS, casein (1 mg/mL, Sigma) and plasminogen (13 $\mu \mathrm{g} / \mathrm{mL}$, American Diagnostica). After electrophoresis, the gel was washed twice in $2.5 \%$ Triton X-100 for 30 min to remove excess SDS, and the caseinolytic proteins were re-natured in situ. The re-natured gel was incubated for $24 \mathrm{~h}$ at room temperature in reaction buffer (20 mM Tris-HCl, pH 7.6). To reveal the caseinolytic activity, the gel was stained with $0.1 \%$ Coomassie brilliant blue R-250 and destained with 20\% methanol and 10\% acetic acid. tPA activity was visualized as light bands resulting from casein degradation. To detect PAI-1 activity by one-phase inverse zymography, the gel was incubated with urokinase-type plasminogen activator (uPA, 0.5 IU/ $\mathrm{mL}$, American Diagnostica) for $5 \mathrm{~h}$ in a reaction buffer, after re-naturation of the SDS-PAGE gel by incubating the gel in $2.5 \%$ Triton X-100 solution. uPA digested the casein in the gel and PAI-1 inhibited the proteolytic action of uPA, leaving dark bands of casein at a molecular weight of $48 \mathrm{kDa}$ after Coomassie blue staining. The gel pictures were taken using the LAS-3000 image detection system (Fuji, Tokyo, Japan) and were inverted for clarity.

\section{Reverse transcription-polymerase chain reaction}

The tPA, Pai-1, iNOS, Mmp9, Il6, and Gapdh mRNA expressions were determined by semi-quantitative reverse transcription-polymerase chain reaction (RT-PCR). The cells were washed twice with ice-cold phosphate buffered saline, and the total RNA was extracted with Trizol (Invitrogen, Carlsbad, CA, USA). First-strand cDNA synthesis was performed using $1 \mu \mathrm{g}$ total RNA and MMuLV reverse transcriptase (MBI Fermentas, Glen Burnie, MD, USA). The reaction was performed at $60^{\circ} \mathrm{C}$ for $60 \mathrm{~min}$ and heated at $97^{\circ} \mathrm{C}$ for $5 \mathrm{~min} ; 1 \mu \mathrm{L}$ from each RT reaction mixture was used for PCR amplification. The primer sequences for $t P A, P a i-1$, iNOS, Mmp9, Il6, and Gapdh were as follows: tPA (NM_013151.2) forward 5'-AGT TGC AGC GAA CCA AGA TG-3', reverse 5'-TGC CAC GGT AAG TCA CAC CT-3' (427 bp); Pai-1 (NM_012620) forward 5'-GCT CCT GGT CAA CCA CCT TA-3', reverse 5'-CCC CAC AAA ATT CAA GAC CA-3' (308 bp); iNOS (NM_012611.3) forward 5'-GCA AGC CCT CAC CTA CTT CC-3', reverse 5'-GGT GCG ATA GGT GAC CAC AG-3' (322 bp); Mmp9 (NM_031055) forward 5'-AAA GGT CGC TCG GAT GGT TA-3', reverse 5'-AGG ATT GTC ATC TGG AGT CGA-3' (320 bp); Il6 (NM_012589) forward 5'CCT TCC TAC CCC AAC TTC CA-3', reverse 5'-TGG AAG TTG GGG TAG GAA GG-3' (472 bp); Gapdh (M17701) forward 5'-TCC CTC AAG ATT GTC AGC AA-3', reverse 5'-AGA TCC ACA ACG GAT ACA TT-3' (308 bp). The PCRs were performed with the following cycle parameters: $94^{\circ} \mathrm{C}, 30 \mathrm{~s} ; 60^{\circ} \mathrm{C}, 1 \mathrm{~min} ; 72^{\circ} \mathrm{C}, 30 \mathrm{~s}, 30$ cycles; and $72^{\circ} \mathrm{C}, 10 \mathrm{~min}$; and Gapdh, $94^{\circ} \mathrm{C}, 30 \mathrm{~s} ; 60^{\circ} \mathrm{C}$, 
$1 \mathrm{~min} ; 72^{\circ} \mathrm{C}, 30 \mathrm{~s}, 22$ cycles; and $72^{\circ} \mathrm{C}, 10 \mathrm{~min}$. All the PCR products were resolved by $1.2 \%$ agarose gel electrophoresis and visualized with ethidium bromide. For quantification, the gels were photographed, and the pixel intensity for each band was determined in Image $\mathrm{NIH}$, Bethesda, MD, USA) and was normalized to the amount of Gapdh mRNA.

\section{Western blot analysis}

Cells were harvested and homogenized in $100 \mu \mathrm{L} /$ well SDS sample buffer containing $62.5 \mathrm{mM}$ Tris- $\mathrm{HCl}$ (pH 6.8), 2\% (w/v) SDS, 10\% glycerol, $50 \mathrm{mM}$ dithiothreitol, $0.1 \%(\mathrm{w} / \mathrm{v})$ bromophenol blue, and $1 \mathrm{mM}$ sodium orthovanadate. After boiling for $5 \mathrm{~min}$, equal amounts of protein were subjected to $10 \%$ SDS-PAGE and the separated proteins were electrophoretically transferred to nitrocellulose membranes (Whatman, Piscataway, NJ, USA) for $90 \mathrm{~min}$. The blot was blocked with 5\% nonfat dried milk at room temperature for $60 \mathrm{~min}$ and subsequently incubated overnight with primary antibodies described in materials section, which were diluted at $1: 2,000$ in $5 \%$ nonfat dried milk at $4^{\circ} \mathrm{C}$. After incubation with horseradish peroxidase-conjugated secondary antibodies at room temperature for $60 \mathrm{~min}$, bands were detected with the enhanced chemiluminescence detection system (Amersham Biosciences, Pescataway, NJ, USA) and exposed to LAS-3000 image detection system (Fuji). Western blotting with a monoclonal antibody against $\beta$-actin (Sigma; 1:50,000 dilution) was used as a loading control.

\section{Statistical analysis}

Results are expressed as mean \pm SEM. Statistical comparisons were performed by one-way ANOVA followed by Tukey's post hoc test using GraphPad Prism ver. 5 (GraphPad Software, San Diego, CA, USA), and a value of $p<0.05$ was considered significant.

A
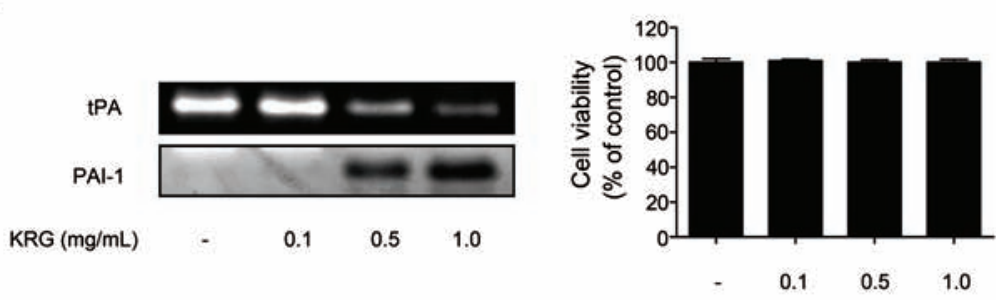

B
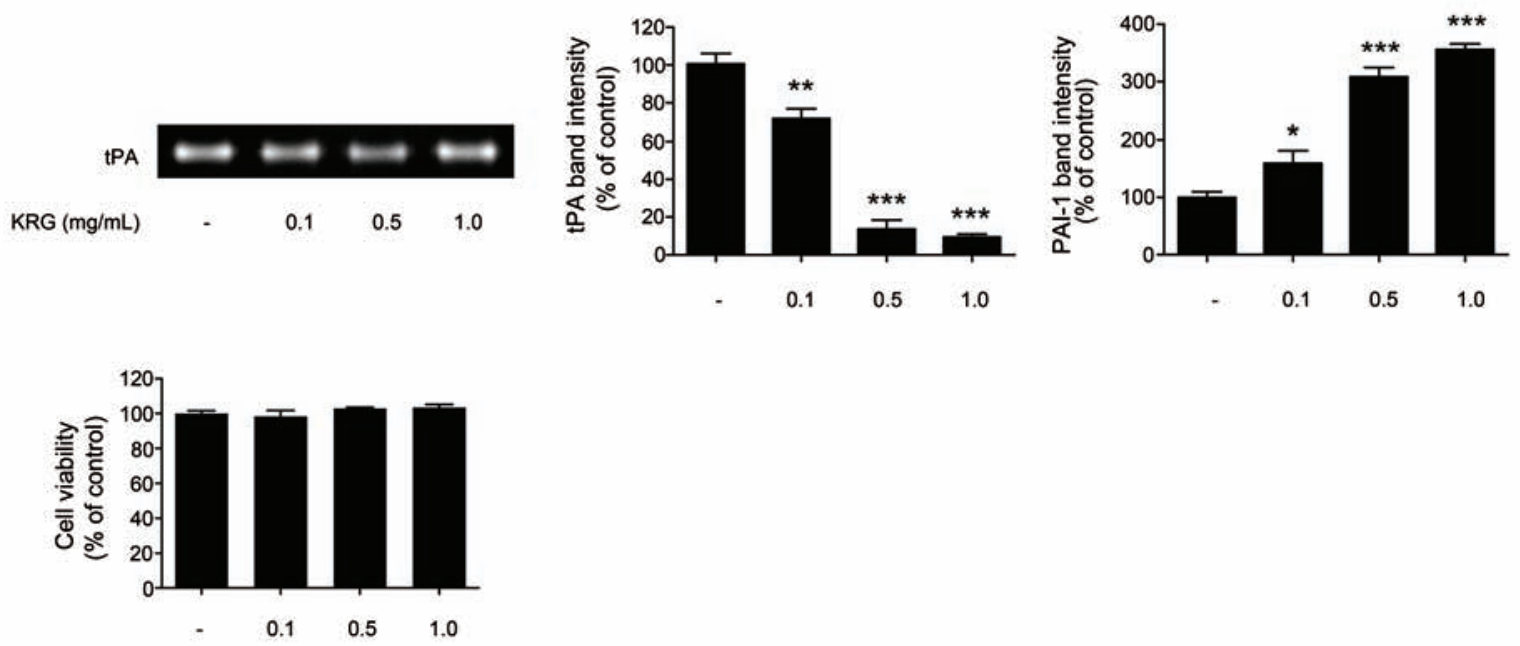

Fig. 1. Effect of Korean Red Ginseng (KRG) on tissue plasminogen activator (tPA)/ plasminogen activator inhibitor-1 (PAI-1) activity and expression in cultured rat primary neuron and astrocytes. (A) Primary cortical neurons in serum-free minimum essential medium were treated with indicated concentrations of KRG $(0.1,0.5$, and $1.0 \mathrm{mg} / \mathrm{mL})$. The culture media were collected at $24 \mathrm{~h}$ after $\mathrm{KRG}$ treatment and were analyzed for tPA activity by casein zymography. Cell viability was measured by MTT (3-[4,5-dimethylthiazol-2-yl]-2,5-diphenyl-tetrazolium bromide) reduction assay. (B) Primary astrocytes in serum-free Dulbecco's modified Eagle medium/F12 were treated with various concentrations of KRG (0.1, 0.5, and $1.0 \mathrm{mg} / \mathrm{mL}$ ). The culture media were collected at $24 \mathrm{~h}$ after KRG treatment and were analyzed for tPA/PAI-1 activity by casein zymography for tPA and one-phase inverse zymography for PAI-1. The graph is the densitometric quantification data of tPA/PAI-1 band intensity. Values are expressed as mean \pm SEM. ${ }^{*} p<0.05,{ }^{* *} p<0.01$, and ${ }^{\star * *} p<0.005$ vs. control $(n=3)$. 


\section{RESULTS}

\section{Effects of Korean Red Ginseng on plasminogen ac- tivator inhibitor-1 and tissue plasminogen activa- tor activity}

To investigate the effects of KRG on TPA/PAI- 1 activity in neuron or astrocytes, we first incubated cultured rat primary neuron or astrocytes with different concentrations of KRG. As we reported previously, cultured neuron only expresses tPA activity [5] and treatment with 0.1-1.0 mg/mL KRG for $24 \mathrm{~h}$ did not have any effects on tPA activity in cultured rat primary neuron (Fig. 1A). The effects of KRG on cell survival were determined by MTT assay and KRG did not affect cell viability of neuron (Fig. 1A). In contrast to neuron, KRG decreased tPA activity with a concomitant increase in PAI-1 activity in rat primary astrocytes in a concentration dependent manner (Fig. 1B) without affecting cell viability (Fig. 1B). Because KRG did not show any effects on tPA activity

A

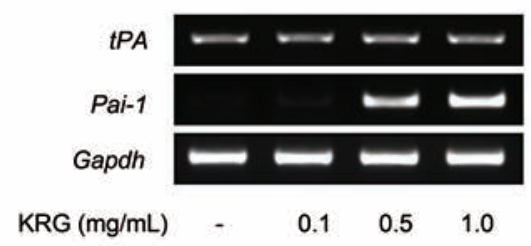

B

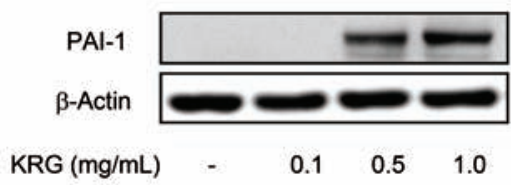

C

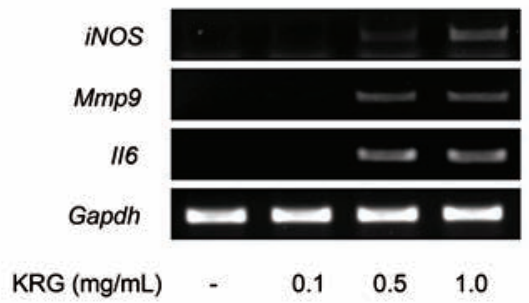

in neuron, we only investigated the effects of KRG on astrocytes thereafter.

Effects of Korean Red Ginseng on plasminogen activator inhibitor-1 and tissue plasminogen activator protein and mRNA expression

We next investigated the effects of KRG on TPA/ PAI-1 expression by RT-PCR and Western blot (Fig. 2). KRG (0.1 to $1.0 \mathrm{mg} / \mathrm{mL}$ ) increased PAI-1 mRNA and protein expression in a concentration-dependent manner (Fig. 2A). At the highest concentration of KRG used in this study $(1.0 \mathrm{mg} / \mathrm{mL})$, the expression of PAI-1 protein was increased $319.3 \pm 66.0 \%$ as compared with control. However, KRG did not affect the expression level of tPA mRNA expression in cultured rat primary astrocytes (Fig. 2A). Combining together with the absence of effects on neuronal tPA activity, which does not express PAI-1 [5], these results suggest that KRG modulates PAI-1 expression, thereby decreasing tPA activity in cultured rat
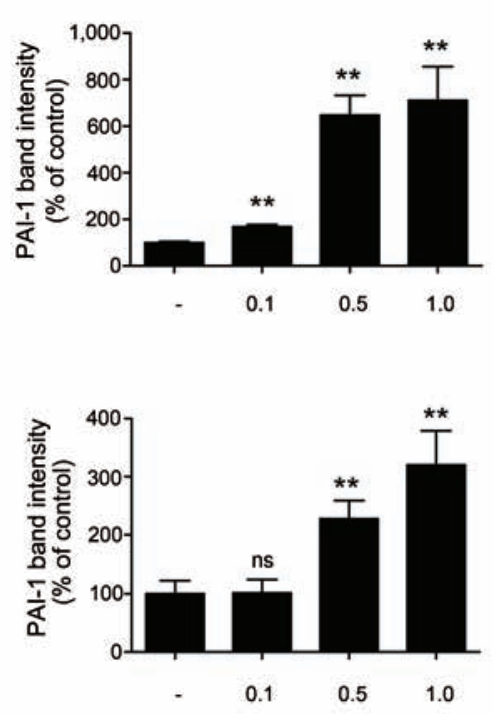

Fig. 2. Effects of Korean Red Ginseng (KRG) on plasminogen activator inhibitor-1 (PAI-1) expression in astrocytes. Rat primary astrocytes in serum-free Dulbecco's modified Eagle medium/F12 were treated with indicated concentrations of KRG (0.1, 0.5, and 1.0 mg/mL). (A) The cultured cells were harvested $24 \mathrm{~h}$ after treatment and analyzed for tPA and Pai-1 mRNA expression by reverse transcription-polymerase chain reaction (RT-PCR). (B) Cell extracts were collected after $24 \mathrm{~h}$ and analyzed for PAI-1 protein expression by Western blot. (C) The cultured cells were harvested after $24 \mathrm{~h}$ and analyzed for iNOS, Mmp9, and $/ 16$ mRNA expression by RT-PCR. The graph is the densitometric quantification data of PAl-1 band intensity. Values are expressed as mean \pm SEM. ${ }^{* *} p<0.01$ vs. control $(n=3)$. ns, no signcance. 
A
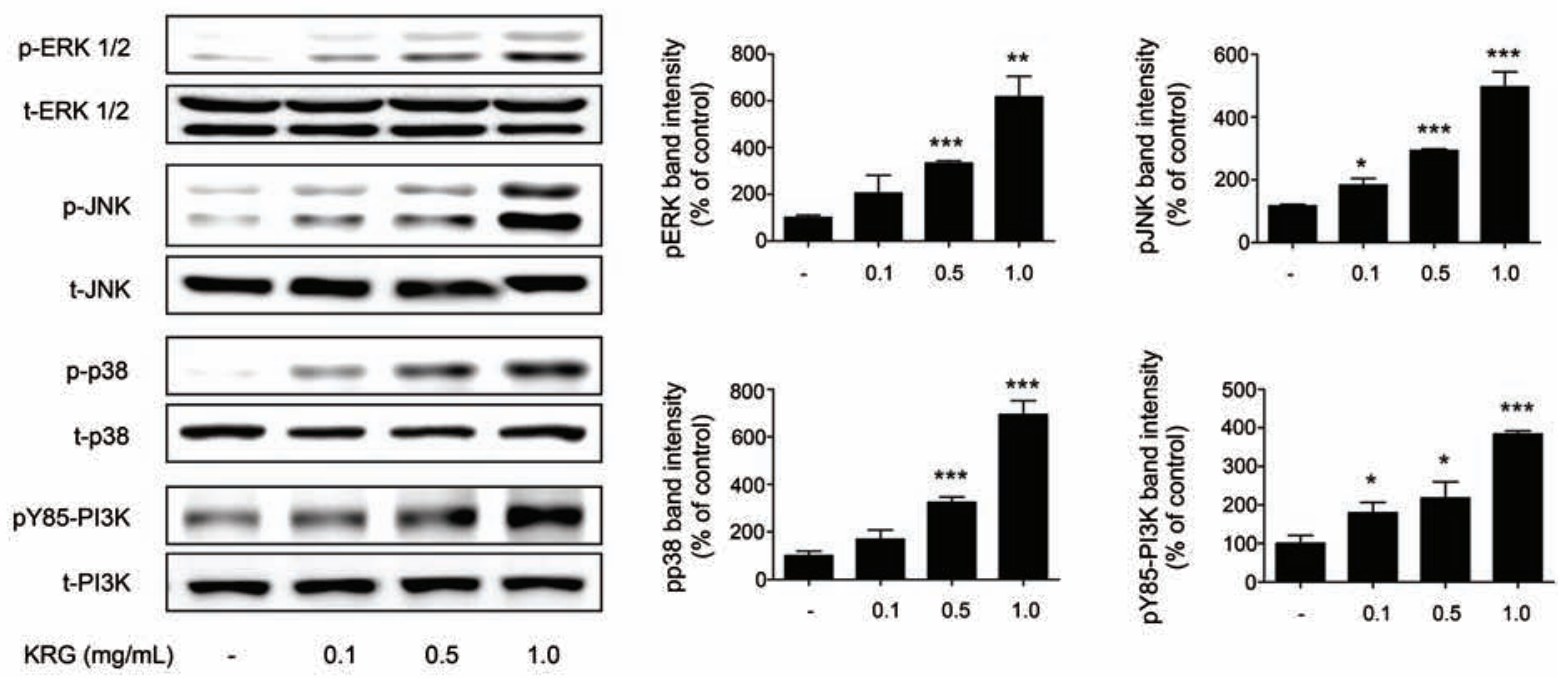

B

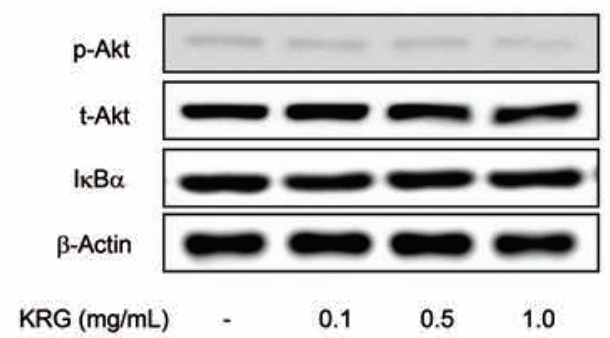

Fig. 3. Activation of MAPKs and PI3K by Korean Red Ginseng (KRG) in rat primary astrocytes. Primary astrocytes in serum-free Dulbecco's modified Eagle medium/F12 were treated with various concentrations of KRG $(0.1,0.5$, and $1.0 \mathrm{mg} / \mathrm{mL})$. (A) Cells were harvested after $1 \mathrm{~h}$ and were analyzed for phosphorylated and total MAPKs and PI3K by Western blot. (B) The level of phospho- and total Akt as well as IkBa. KRG did not affect phosphorylation of Akt and the level of IkBa. The graph is the densitometric quantification data of phosphorylated and total MAPKs and $\mathrm{PI} 3 \mathrm{~K}$ band intensity. Values are expressed as mean \pm SEM. ${ }^{*} p<0.05,{ }^{* *} p<0.01$, and ${ }^{* *} p<0.005$ vs. control $(n=3)$.

primary astrocytes. Because immunological stimulation and activation of astrocytes may induce the expression of PAI-1 in rat primary astrocytes as reported previously $[5,19,20]$, we examined the expression of several inflammatory mediators produced in rat primary astrocytes after treatment of KRG (Fig. 2B). Similar to the upregulation of Pai-1 expression by KRG, there is a weak but significant increase in the expression of inflammatory mediators such as iNOS, Mmp-9 and Il6, suggesting activation of inflammatory activation response by KRG in rat primary astrocytes.

\section{Signaling pathway regulating plasminogen activa- tor inhibitor-1 expression}

To investigate the signaling pathway regulating PAI1 expression by KRG in rat primary astrocytes, we examined the activation of PI3K and MAPK pathways by KRG. All three subfamilies of MAPKs pathway, namely p38, JNK, and Erk1/2 was activated by KRG in a concentration-dependent manner as evidenced by increased phosphorylation of each MAPK families (Fig. 3A). Activation of PI3K pathway has also been observed but there was no activation of Akt pathway (Fig. 3). Degradation of IкB $\alpha$ was not observed in astrocytes treated with KRG, suggesting activation of NFKB pathway is not the major signaling pathways regulating the activation of astrocytes and up-regulation of PAI-1 expression in rat primary astrocytes by KRG. Pretreatment of 10 $\mu \mathrm{M}$ SB203580, SP600125, and U0126, inhibitors of p38, JNK and Erk1/2 MAPKs, respectively, prevented $1.0 \mathrm{mg} /$ mL KRG-induced expression of PAI-1, which also resulted in the restoration of tPA activity (Fig. 4A). Similarly, a PI3K inhibitor LY294002 $(10 \mu \mathrm{M})$ inhibited KRGinduced induction of PAI-1 and decrease in PAA activity in rat primary astrocytes (Fig. 4A). Consistent with the effects on PAI-1 activity, pretreatment with SB203580, 
A

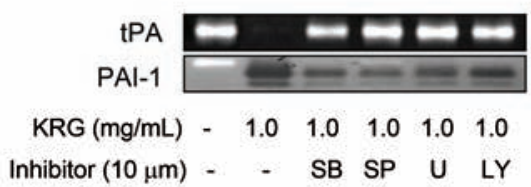

B
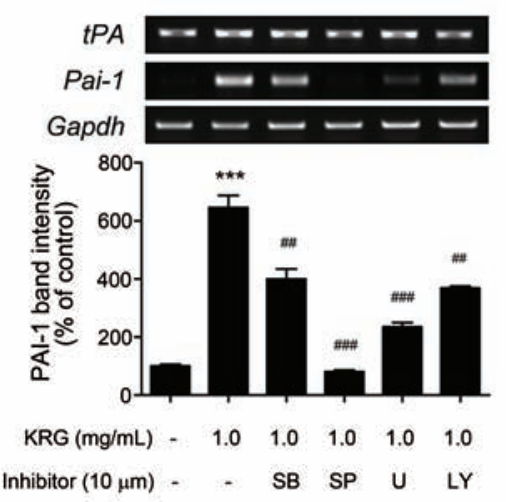

D

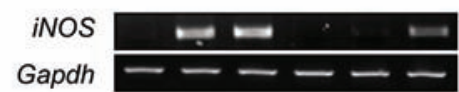

$\mathrm{KRG}(\mathrm{mg} / \mathrm{mL}) \quad-\quad \begin{array}{lllll}1.0 & 1.0 & 1.0 & 1.0 & 1.0\end{array}$

Inhibitor $(10 \mu \mathrm{m})$ - - SB SP U LY
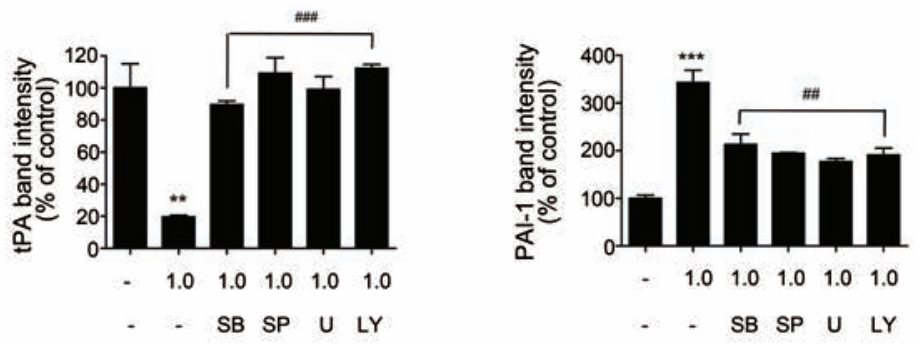

C
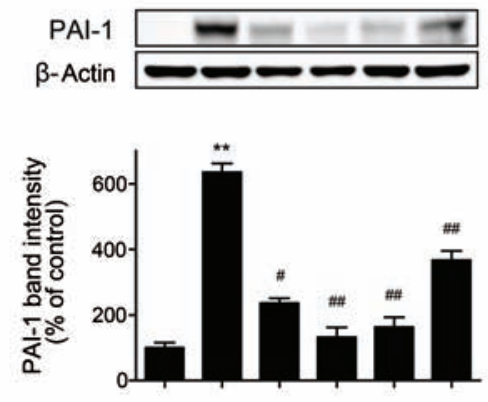

$\mathrm{KRG}(\mathrm{mg} / \mathrm{mL}) \quad-\quad \begin{array}{lllll}1.0 & 1.0 & 1.0 & 1.0 & 1.0\end{array}$

Inhibitor $(10 \mu \mathrm{m})$ - - SB SP U LY

iNOS

$\beta$-actin

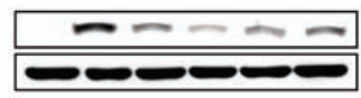

KRG (mg/mL) - $\begin{array}{lllllll}1.0 & 1.0 & 1.0 & 1.0 & 1.0\end{array}$

Inhibitor $(10 \mu \mathrm{m})$ - - SB SP U LY

Fig. 4. MAPKs inhibitors and PI3K inhibitor inhibited Korean Red Ginseng (KRG)-induced induction of plasminogen activator inhibitor-1 (PAI1) in rat primary astrocytes. Astrocytes were treated with $1.0 \mathrm{mg} / \mathrm{mL} \mathrm{KRG} \mathrm{for} 24 \mathrm{~h}$. SB203580 (a p38 MAPK inhibitor, $10 \mu \mathrm{M}$ ), U0126 (a MEK1/2 inhibitor, $10 \mu \mathrm{M}$ ), SP600125 (a JNK inhibitor, $10 \mu \mathrm{M}$ ) or LY294002 (a PI3K inhibitor, $10 \mu \mathrm{M}$ ) were pre-treated 30 min before KRG application. (A) The culture media were collected at $24 \mathrm{~h}$ after KRG treatment and analyzed for tissue plasminogen activator (tPA)/plasminogen activator inhibitor (PAI-1) activity by casein zymography (tPA) and one-phase inverse zymography (PAl-1). (B,D) The cells were harvested after $24 \mathrm{~h}$ and were analyzed for $T P A, P a i-1$, and iNOS mRNA expression by reverse transcription-polymerase chain reaction. $(C, D)$ Cell extracts were collected after $24 \mathrm{~h}$ and analyzed for PAI-1 and iNOS protein expression by Western blot. The graph is the densitometric quantification data of tPA/PAI-1 band intensity. Values are expressed as mean \pm SEM. SB203580 (a p38 MAPK inhibitor), U0126 (a MEK1/2 inhibitor), SP600125 (a JNK inhibitor, or LY294002 (a PI3K inhibitor). ${ }^{* *} p<0.01$ and ${ }^{* * *} p<0.005$ vs. control $(n=3)$ and ${ }^{*} p<0.05,{ }^{\# \#} p<0.01$, and ${ }^{\# \# \#} p<0.005$ vs. KRG $(n=3)$.

SP600125, U0126, and LY294002 prevented $1.0 \mathrm{mg} / \mathrm{mL}$ KRG-induced expression of PAI-1 mRNA (Fig. 4B). All the inhibitors did not show any effects on tPA mRNA expression level (Fig. 4B). When we examined the expression level of PAI-1 by Western blot, pretreatment with SB203580, SP600125, U0126, and LY294002 inhibited $1.0 \mathrm{mg} / \mathrm{mL}$ KRG-induced expression of PAI-1 protein (Fig. 4C). We also examined the effects of above inhibitors on iNOS protein and mRNA expression (Fig. 4D). In contrast to the global inhibitory effects of MAPK and PI3K inhibitors on PAI-1 protein and mRNA expression, SP600125 and U0126, and to a lesser extent LY294002 but not SB203580 inhibited iNOS mRNA and protein expression, as determined by RT-PCR and Western blot, respectively (Fig. 4D).

\section{Lipopolysaccharide contamination is not related to the Korean Red Ginseng-induced up-regulation of plasminogen activator inhibitor-1 activity}

Because many herbal medicine or natural compound preparations may be contaminated with strong inflammatory stimulants such as LPS, a bacterial cell wall component, we tried to check whether LPS is contaminated in our KRG preparation using polymixin B, a chemical binds and inactivates LPS. As shown in Fig. 5A, $30 \mathrm{ng} /$ $\mathrm{mL}$ polymixin B effectively inhibited $10 \mathrm{ng} / \mathrm{mL}$ LPS-in- 
A

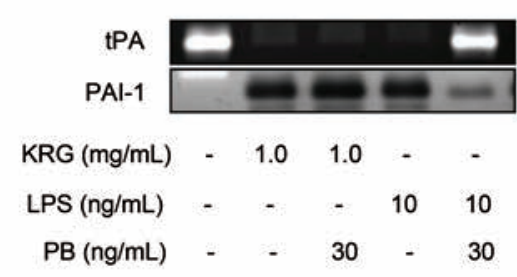

B

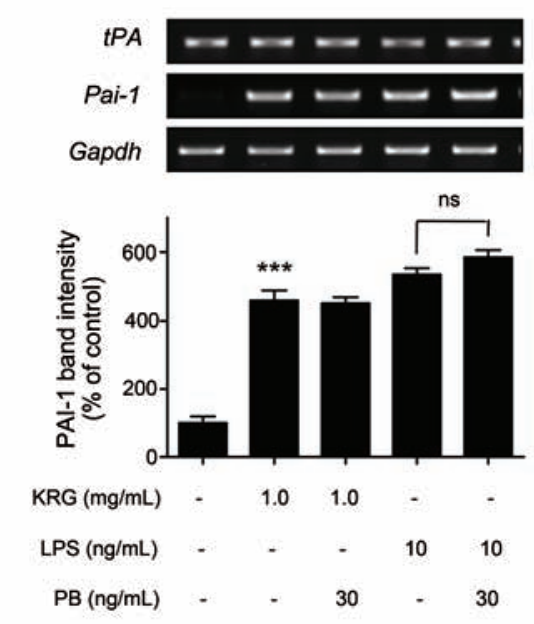

D

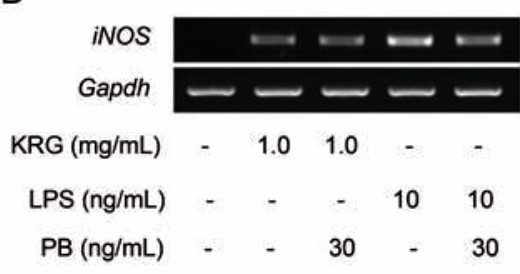

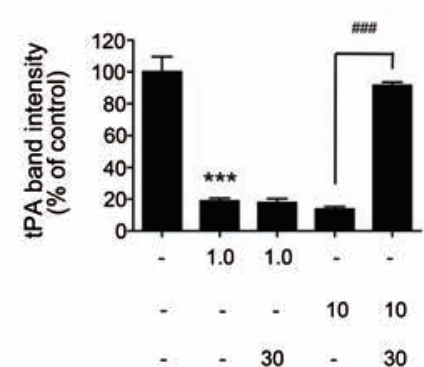

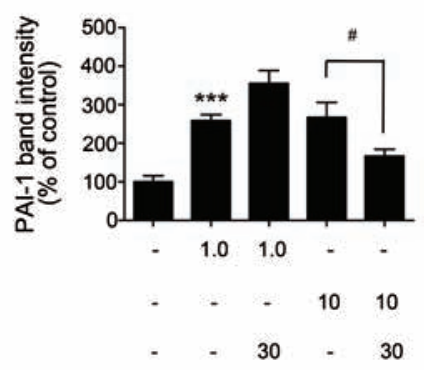

C
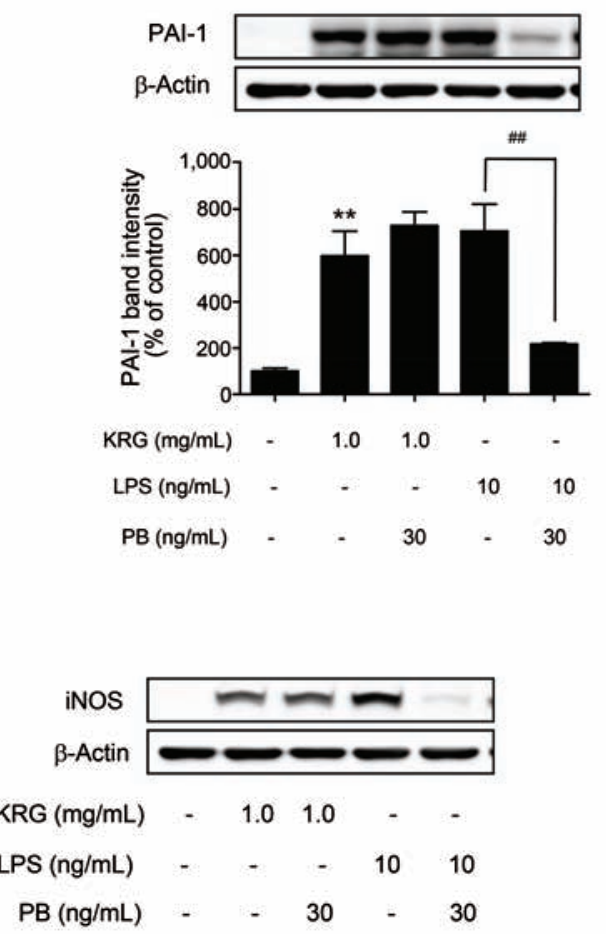

Fig. 5. Inhibition of lipopolysaccharide (LPS)-induced but not Korean Red Ginseng (KRG)-induced plasminogen activator inhibitor-1 (PAI-1) induction by polymixin B (PB). Astrocytes were treated with KRG $(1.0 \mathrm{mg} / \mathrm{mL})$ and LPS $(10 \mathrm{ng} / \mathrm{mL})$ for $24 \mathrm{~h}$. Polymixin B (a endotoxin blocker, 30 $\mathrm{ng} / \mathrm{mL}$ ) were pretreated 30 min before KRG or LPS application. (A) The culture media were collected at $24 \mathrm{~h}$ after KRG treatment and analyzed for tissue plasminogen activator (tPA)/plasminogen activator inhibitor-1 (PAI-1) activity by casein zymography (tPA) and one-phase inverse zymography (PAI-1). (B,D) The cells were harvested after $24 \mathrm{~h}$ and were analyzed for $t P A, P a i-1$, and iNOS mRNA expression by reverse transcription-polymerase chain reaction. (C,D) The cultured cells were harvested after $24 \mathrm{~h}$ and were analyzed for PAI-1 and iNOS protein expression by Western blot. The graph is the densitometric quantification data of tPA/PAI-1 band intensity. Values are expressed as mean \pm SEM. ${ }^{* *} p<0.01$ and ${ }^{* \star *} p<0.005$ vs. control $(n=3)$ and ${ }^{\#} p<0.05,{ }^{\# \#} p<0.01$, and ${ }^{\# \#} p<0.005$ vs. LPS $(n=3)$. ns, no signcance.

duced up-regulation of PAI-1 activity (Fig. 5A), mRNA (Fig. 5B) and protein expression (Fig. 5C) as well as other inflammatory mediators such as iNOS (Fig. 5D). In contrast, polymixin B were without effects on KRGinduced PAI-1 up-regulation (Fig. 5A-C), tPA downregulation (Fig. 5A) or iNOS induction (Fig. 5D). These results suggest that LPS contamination is not related to the KRG-induced up-regulation of PAI-1 activity.

\section{Compound $\mathrm{K}$ regulates plasminogen activator in- hibitor-1 expression}

We next investigated the role of individual ginsenosides on PAI-1 expression in rat primary astrocytes. Among three genisenosides (CK, Rb1, and Rg1) used in this study (Fig. 6A-C), only CK induced a significant upregulation of PAI-1 (and hence down regulation of tPA) activity in rat primary astrocytes (Fig. 6A). As expected, 
A

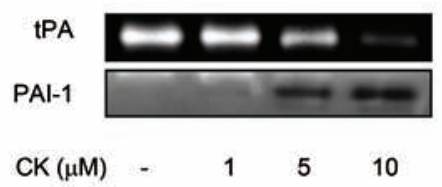

B

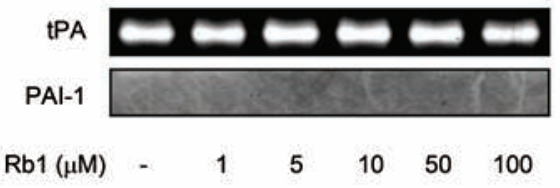

D

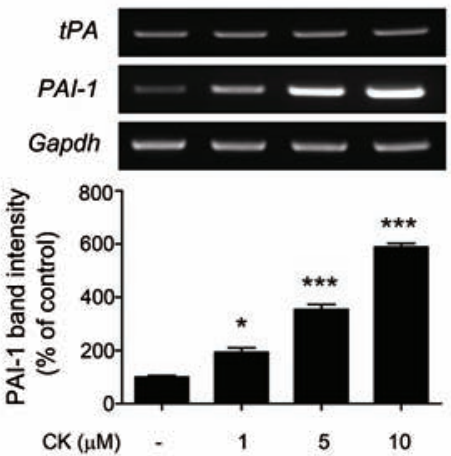

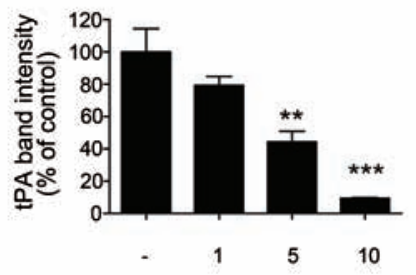

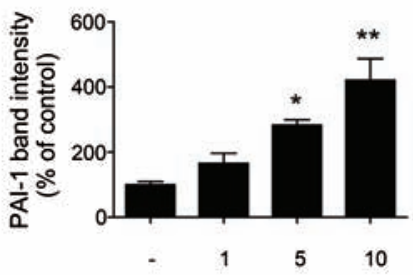

C

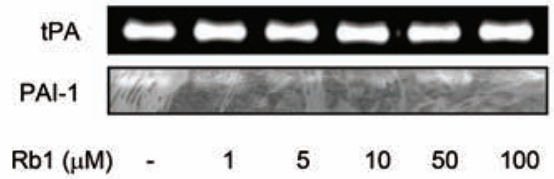

$\mathrm{E}$

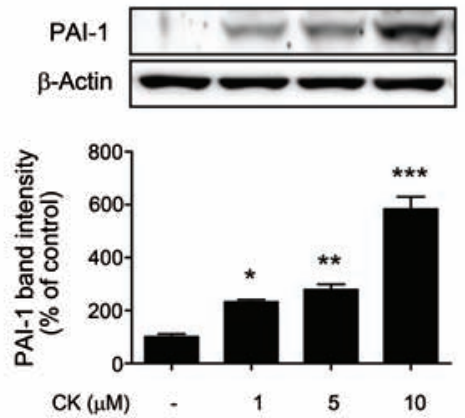

Fig. 6. Effects of compound $\mathrm{K}(\mathrm{CK})$ on plasminogen activator inhibitor-1 (PAI-1) expression in astrocytes. Rat primary astrocytes in serum-free Dulbecco's modified Eagle medium/F12 were treated with indicated concentrations of $\mathrm{CK}(1,5$, and $10 \mu \mathrm{M}), \mathrm{Rb} 1(1,5,10,50$, and $100 \mu \mathrm{M})$, and $\operatorname{Rg} 1(1,5,10,50$, and $100 \mu \mathrm{M})$. (A-C) The culture media were collected at $24 \mathrm{~h}$ after CK (A), Rb1 (B), or Rg1 (C). Treatment and were analyzed for tissue plasminogen activator (tPA)/plasminogen activator inhibitor-1 (PAI-1) activity by casein zymography for tPA and one-phase inverse zymography for PAI-1. (D) The cultured cells were harvested $24 \mathrm{~h}$ after CK treatment and analyzed for TPA and Pai-1 mRNA expression by reverse transcription-polymerase chain reaction. (E) Cell extracts were collected at $24 \mathrm{~h}$ after CK treatment and analyzed for PAI-1 protein expression by Western blot. The graph is the densitometric quantification data of tPA/PAI-1 band intensity. Values are expressed as mean \pm SEM. ${ }^{*} p<0.05$, ${ }^{\star *} p<0.01$, and ${ }^{* \star *} p<0.005$ vs. control $(n=3)$.

CK also induced PAI-1 mRNA and protein expression in rat primary astrocytes in a concentration dependent manner (Fig. 6D, E). These results suggest that CK might be one of the main ginsenosides capable of regulating tPA/ PAI-1 activity in rat primary astrocytes.

\section{DISCUSSION}

Although there are mixed reports on the role of individual components from ginseng in tPA system in endothelial or peripheral tissues [11,14,15,21,22], this is the first report describing the effects of KRG on tPA/ PAI-1 system in neuron and astrocytes. Although we did not find changes in tPA expression by KRG, there was decrease in tPA activity due to the up-regulation of PAI1 in rat primary astrocytes, which is also recapitulated with CK. In cultured endothelial cells, total ginseng saponin and individual saponins such as ginsenoside Rg1 and $\mathrm{Rb} 1$ has been reported to increase the release of tPA $[11,22]$. In addition, inconsistent results were reported on the regulation of PAI-1 by ginseng saponins, which showed no changes, increased or decreased expression in endothelial or smooth muscle cells $[11,14,15]$. These results suggest that the regulation of tPA/PAI- 1 by different preparations of ginseng or ginseng saponins is modulated in a cell type- or stimulus protocol-dependent manners.

The diverse physiological and pathological action of tPA/PAI-1 includes regulation of neurite outgrowth, 
activation of trophic factors, regulation of cell migration during development, regulation of synaptic plasticity, modulation of apoptosis or cell death, clearance of $A \beta$ peptide, too much to mention them all [23]. Therefore, the activity of tPA/PAI-1 should be tightly regulated and astrocytes, the main CNS cell type expressing PAI-1, may fine-tune the regulation of tPA activity by modulating the level of PAI-1 [5]. Moreover, increased PAI1 activity and expression might be both positively and negatively involved in the cell migration, axonal growth and cell death depending on the differential cell types and experimental conditions used. Therefore, final outcome of PAI-1 induction in astrocytes on neuronal cell survival and modulation of CNS function would be delicately modulated by differences in kinetic profile of PAI-1 and tPA activity as well as the local concentration of both molecules in the context of physiological or pathological changes in brain tissues.

In this study, KRG induced PAI-1 expression as well as other inflammatory mediators such as iNOS and MMP-9 in astrocytes. In immunologically stimulated condition such as cerebral ischemia, ginseng or ginsenosides has been reported to protect brain by anti-inflammatory action [24,25]. In our condition, along with massive PAI-1 induction, a weak induction of inflammatory mediators such as iNOS was observed. The induction of iNOS might be explained by the difference of the effects of ginseng on basal and immune-stimulated conditions. For example, red ginseng acidic polysaccharide components activated macrophage in basal status. However, it slightly but significantly inhibited LPS-induced activation of macrophage [26]. Similar to our results, treatment of Rg3 induced expression of iNOS and NO production in Raw264.7 cells as well as in vascular smooth muscle cells [27]. Further studies are required to unequivocally prove the role of ginseng-induced changes in tPA/PAI-1 system in basal and immunologically challenged situation.

In this study, activation of MAPK and PI3K by KRG induced the expression of PAI-1. In our previous study, we reported the essential role of Erk1/2 in the regulation of PAI- 1 by $\alpha$-synuclein [28]. In the present study, all three members of MAPK pathway, i.e., p38, Erk1/2 and JNK were involved in the regulation of PAI-1 induction by KRG in rat primary astrocytes. The use of crude extract of $P$. ginseng, which contains a variety of different components, may account for the activation of all three MAPK pathways, as well as the differential effect of specific pharmacological inhibitors such as SP600125 on PAI-1 expression and activity. The involvement of all three members of MAPK in the regulation of PAI-1 is not unprecedented. In a model system of plasminogeninduced expression of PAI-1 in rat primary astrocytes, the involvement of multiple MAPK pathways has been suggested [29,30]. In PAR-2 activated NO production in astrocytes, all three MAPK pathways were also involved suggesting they can regulate same intracellular target proteins through either pathway alone or in combination with other members [31]. In this study, we found KRG activated PI3K pathway but there was no changes in Akt phosphorylation. Even though Akt is generally regarded as immediate downstream of PI3K pathway, the independent regulation of PI3K and Akt by KRG in this study suggests that KRG may affect the activity of other regulators of Akt activation such as mTOR2C, PDK1 and PP2A, which needs experimental verification in the future.

Although all the MAPK and PI3K inhibitors prevented PAI-1 induction by KRG, the strongest inhibition was observed with SP600125, which is a JNK inhibitor. The result might suggest the essential role of JNK in the regulation of KRG-induced PAI-1 expression. In case of plasminogen-induced upregulation of PAI-1 in astrocytes, Nakajima et al. [29] reported p38 and JNK but not ERK1/2 play major role in the up-regulation of PAI-1 [31]. In RAW264.7 cells, SP600125 efficiently inhibited red ginseng acidic polysaccharide (RGAP)-induced NO production suggesting the role of JNK activation in mediating RGAP-induced macrophage activation [26]. KRG consists of various ginsenoside components including Rg1, Rb1, Rc, Rf, Re, Rb2, and Rg2, which may differentially regulate signaling pathways and PAI-1 expression. Recent reports suggested an array of different effects of individual ginsenosides on JNK activity in many cell types; i.e., no effects by Rh2 [32], inhibition by Rb1 [33], and activation by Rg3 or CK [34,35]. Interestingly, we did not observe any effects of Rb1 and Rg1 on PAI-1 activity in rat primary astrocytes. Instead, CK, a metabolite of the protopanaxadiol-type saponins of $P$. ginseng, strongly induced PAI-1 activity as well as mRNA and protein expression, thereby down-regulating tPA activity in rat primary astrocytes. Dissection of the role of individual components of KRG on the regulation of activation of signaling pathways and PAI-1 expression may provide us more definite answer regarding the molecular mechanism of KRG-induced regulation of PAI-1 expression.

KRG and CK induced PAI-1 expression in cultured rat primary astrocytes. Although the functional significance of the elevated PAI-1 expression in astrocytes by KRG 
on brain function and responses to pathological insults should be experimentally investigated in the future, the results from the present study suggest that regulation of tPA/PAI-1 activity by pretreatment of KRG may position the balance of tPA/PAI-1 activity in brain in a way beneficial for the challenged situation. PAI-1 regulates overall tPA activity in brain, which may play important role in stimulus or inflammation induced neuronal cell death in ischemic or neurodegenerative condition [36,37]. It is also reported that $\mathrm{PA}$ activity is essential in the process of addiction [23]. Therefore, PAI-1-induced down-regulation of tPA activity by KRG may contribute to protect neuron from cell death in ischemia and traumatic brain injury as well as inhibiting manifestation of addiction to drugs of abuse. In addition, considering the essential role of tPA/PAI-1 in the regulation of endothelial permeability, the regulation of PAI-1 activity in astrocytes by $\mathrm{KRG}$ may play important roles in the final pathological outcome in cerebrovascular diseases.

\section{ACKNOWLEDGEMENTS}

This work was supported by a grant of the Korean Health Technology R\&D Project, Ministry of Health and Welfare, Republic of Korea (no. A120029).

\section{REFERENCES}

1. Sofroniew MV, Vinters HV. Astrocytes: biology and pathology. Acta Neuropathol 2010;119:7-35.

2. Yepes M, Lawrence DA. New functions for an old enzyme: nonhemostatic roles for tissue-type plasminogen activator in the central nervous system. Exp Biol Med (Maywood) 2004;229:1097-1104.

3. Samson AL, Medcalf RL. Tissue-type plasminogen activator: a multifaceted modulator of neurotransmission and synaptic plasticity. Neuron 2006;50:673-678.

4. Lemarchant S, Docagne F, Emery E, Vivien D, Ali C, Rubio $\mathrm{M}$. tPA in the injured central nervous system: different scenarios starring the same actor? Neuropharmacology 2012;62:749-756.

5. Kim JW, Lee SH, Ko HM, Kwon KJ, Cho KS, Choi CS, Park JH, Kim HY, Lee J, Han SH et al. Biphasic regulation of tissue plasminogen activator activity in ischemic rat brain and in cultured neural cells: essential role of astrocyte-derived plasminogen activator inhibitor-1. Neurochem Int 2011;58:423-433.

6. Wee JJ, Mee Park K, Chung AS. Biological activities of ginseng and its application to human health. In: Benzie IF, Wachtel-Galor S, eds. Herbal medicine: biomolecular and clinical aspects. 2nd ed. Boca Raton: CRC Press, 2011. p.157-174.

7. Radad K, Moldzio R, Rausch WD. Ginsenosides and their CNS targets. CNS Neurosci Ther 2011;17:761-768.

8. Radad K, Gille G, Liu L, Rausch WD. Use of ginseng in medicine with emphasis on neurodegenerative disorders. J Pharmacol Sci 2006;100:175-186.

9. Chen CF, Chiou WF, Zhang JT. Comparison of the pharmacological effects of Panax ginseng and Panax quinquefolium. Acta Pharmacol Sin 2008;29:1103-1108.

10. Nah SY, Kim DH, Rhim H. Ginsenosides: are any of them candidates for drugs acting on the central nervous system? CNS Drug Rev 2007;13:381-404.

11. He F, Guo R, Wu SL, Sun M, Li M. Protective effects of ginsenoside Rb1 on human umbilical vein endothelial cells in vitro. J Cardiovasc Pharmacol 2007;50:314-320.

12. Morisaki N, Watanabe S, Tezuka M, Zenibayashi M, Shiina R, Koyama N, Kanzaki T, Saito Y. Mechanism of angiogenic effects of saponin from ginseng Radix rubra in human umbilical vein endothelial cells. Br J Pharmacol 1995;115:1188-1193.

13. Nakajima S, Uchiyama Y, Yoshida K, Mizukawa H, Haruki E. The effects of ginseng Radix rubra on human vascular endothelial cells. Am J Chin Med 1998;26:365-373.

14. Zhang HS, Wang SQ. Notoginsenoside R1 from Panax notoginseng inhibits TNF-alpha-induced PAI-1 production in human aortic smooth muscle cells. Vascul Pharmacol 2006;44:224-230.

15. Zhang W, Wojta J, Binder BR. Effect of notoginsenoside R1 on the synthesis of tissue-type plasminogen activator and plasminogen activator inhibitor-1 in cultured human umbilical vein endothelial cells. Arterioscler Thromb 1994;14:1040-1046.

16. Zhang WJ, Wojta J, Binder BR. Effect of notoginsenoside $\mathrm{R} 1$ on the synthesis of components of the fibrinolytic system in cultured smooth muscle cells of human pulmonary artery. Cell Mol Biol (Noisy-le-grand) 1997;43:581-587.

17. Kim P, Park JH, Kwon KJ, Kim KC, Kim HJ, Lee JM, Kim HY, Han SH, Shin CY. Effects of Korean red ginseng extracts on neural tube defects and impairment of social interaction induced by prenatal exposure to valproic acid. Food Chem Toxicol 2013;51:288-296.

18. Shin CY, Choi JW, Ryu JR, Ryu JH, Kim W, Kim H, Ko $\mathrm{KH}$. Immunostimulation of rat primary astrocytes decreases intracellular ATP level. Brain Res 2001;902:198204.

19. Hultman K, Blomstrand F, Nilsson M, Wilhelmsson U, Malmgren K, Pekny M, Kousted T, Jern C, TjarnlundWolf A. Expression of plasminogen activator inhibitor-1 and protease nexin-1 in human astrocytes: response to 
injury-related factors. J Neurosci Res 2010;88:2441-2449.

20. Lee SY, Kim HJ, Lee WJ, Joo SH, Jeon SJ, Kim JW, Kim HS, Han SH, Lee J, Park SH et al. Differential regulation of matrix metalloproteinase-9 and tissue plasminogen activator activity by the cyclic-AMP system in lipopolysaccharide-stimulated rat primary astrocytes. Neurochem Res 2008;33:2324-2334.

21. Xin X, Liu J, Li X, Zhong J, Wei D. Extraction of 20(S)ginsenoside Rg2 from cultured Panax notoginseng cells in vitro stimulates human umbilical cord vein endothelial cell proliferation. Am J Ther 2006;13:205-210.

22. Ushio Y. Effect of ginsenoside Rgl on the release of enzymes by cultured endothelial cells. Am J Chin Med 1992;20:91-101.

23. Melchor JP, Strickland S. Tissue plasminogen activator in central nervous system physiology and pathology. Thromb Haemost 2005;93:655-660.

24. Joo SS, Yoo YM, Ahn BW, Nam SY, Kim YB, Hwang KW, Lee DI. Prevention of inflammation-mediated neurotoxicity by Rg3 and its role in microglial activation. Biol Pharm Bull 2008;31:1392-1396.

25. Park JS, Shin JA, Jung JS, Hyun JW, Van Le TK, Kim DH, Park EM, Kim HS. Anti-inflammatory mechanism of compound $\mathrm{K}$ in activated microglia and its neuroprotective effect on experimental stroke in mice. J Pharmacol Exp Ther 2012;341:59-67.

26. Byeon SE, Lee J, Kim JH, Yang WS, Kwak YS, Kim SY, Choung ES, Rhee MH, Cho JY. Molecular mechanism of macrophage activation by red ginseng acidic polysaccharide from Korean red ginseng. Mediators Inflamm 2012;2012:732860.

27. Kim ND, Kim EM, Kang KW, Cho MK, Choi SY, Kim SG. Ginsenoside Rg3 inhibits phenylephrine-induced vascular contraction through induction of nitric oxide synthase. Br J Pharmacol 2003;140:661-670.

28. Joo SH, Kwon KJ, Kim JW, Kim JW, Hasan MR, Lee HJ, Han SH, Shin CY. Regulation of matrix metalloproteinase- 9 and tissue plasminogen activator activity by alpha-synuclein in rat primary glial cells. Neurosci Lett 2010;469:352-356.

29. Nakajima K, Yamamoto S, Tohyama Y, Kohsaka S. Close association of p38 and JNK with plasminogen-dependent upregulation of PAI-1 in rat astrocytes in vitro. Neurosci Lett 2010;471:66-69.

30. Kim YM, Namkoong S, Yun YG, Hong HD, Lee YC, Ha KS, Lee H, Kwon HJ, Kwon YG, Kim YM. Water extract of Korean red ginseng stimulates angiogenesis by activating the PI3K/Akt-dependent ERK1/2 and eNOS pathways in human umbilical vein endothelial cells. Biol Pharm Bull 2007;30:1674-1679.

31. Park GH, Jeon SJ, Ryu JR, Choi MS, Han SH, Yang SI, Ryu JH, Cheong JH, Shin CY, Ko KH. Essential role of mitogen-activated protein kinase pathways in protease activated receptor 2-mediated nitric-oxide production from rat primary astrocytes. Nitric Oxide 2009;21:110-119.

32. He L, Lee J, Jang JH, Lee SH, Nan MH, Oh BC, Lee SG, Kim HH, Soung NK, Ahn JS et al. Ginsenoside Rh2 inhibits osteoclastogenesis through down-regulation of NF$\kappa B$, NFATc1 and c-Fos. Bone 2012;50:1207-1213.

33. Li J, Shao ZH, Xie JT, Wang CZ, Ramachandran S, Yin JJ, Aung H, Li CQ, Qin G, Vanden Hoek T et al. The effects of ginsenoside Rb1 on JNK in oxidative injury in cardiomyocytes. Arch Pharm Res 2012;35:1259-1267.

34. Hien TT, Kim ND, Pokharel YR, Oh SJ, Lee MY, Kang KW. Ginsenoside Rg3 increases nitric oxide production via increases in phosphorylation and expression of endothelial nitric oxide synthase: essential roles of estrogen receptor-dependent PI3-kinase and AMP-activated protein kinase. Toxicol Appl Pharmacol 2010;246:171-183.

35. Lee IK, Kang KA, Lim CM, Kim KC, Kim HS, Kim DH, Kim BJ, Chang WY, Choi JH, Hyun JW. Compound K, a metabolite of ginseng saponin, induces mitochondriadependent and caspase-dependent apoptosis via the generation of reactive oxygen species in human colon cancer cells. Int J Mol Sci 2010;11:4916-4931.

36. Yang D, Nemkul N, Shereen A, Jone A, Dunn RS, Lawrence DA, Lindquist D, Kuan CY. Therapeutic administration of plasminogen activator inhibitor-1 prevents hypoxic-ischemic brain injury in newborns. J Neurosci 2009;29:8669-8674.

37. Scheibe F, Klein O, Klose J, Priller J. Mesenchymal stromal cells rescue cortical neurons from apoptotic cell death in an in vitro model of cerebral ischemia. Cell Mol Neurobiol 2012;32:567-576. 